\title{
Depression and Suicide into Adolescence (12-18) years in Rehabilitation Health Center, in AL-Hilla City
}

\author{
Abdul Mahdi A. Hasan
}

Department of Paediatric and Mental Health Nursing, College of Nursing, University of Babylon, Hilla City.

correspondence to Abdul Mahdi A. Hasan (email: abd_mahdi2003@yahoo.com).

(Submitted: 29 September 2016 - Revised version received: 15 October 2016 - Accepted: 18 February 2017 - Published online: 26 March 2017)

\begin{abstract}
Objectives To identify patients' demographical data for the assessment of depression and suicide in adolescence, and to address over the pressure negative consequences.

Methods Descriptive design study was used to the patients with depression and suicide among adolescent (12-18)years with psychological stress that effect his life style descriptive study used (50) patient brood, randomly selected, and the data collected during the interview with the disease by demographic data included a questionnaire and an elaborate global survey. The data were analyzed by statistical methods, which included frequencies, percentage. The purpose of the study was to evaluate depression and suicide in adolescences, and recommend paying attention to the psychological state of adolescences depression and suicide in adolescence in health center. This study was carried out in the health center during (from November 18, 2015 to January 12, 2016).

Results Depression was higher in this study than other studies, higher prevalence of depression in adolescences patients with age between 17 and 18 years (46\%). 50\% of patients feel the sadness and depression. $50 \%$ of patients feel unhappy to the degree painful. $40 \%$ of patients feel disappointed in their self. $45 \%$ of patients are thinking about suicide. $41 \%$ of patients fear for their health and physical pain to the point of worrying. Conclusion The result shows that the study recommends need to work on early detection of depressive symptoms to adolescences. It also emphasizes that the negligence of the diagnostic process symptoms in this age group leads to insanity and suicide to involve young people as possible causes of culture. Since this leads to self-promote as well as reduces the decrease of pessimism and isolation. This would alleviate the depressive symptoms. Attention to psychosocial and social support for young people, by creating a state of confidence as well as through the establishment of altrohed and programs that reduce the cases of grief and depression symptoms and work on understanding to the explain of emotions and its problems, difficulties experienced, discuss the reasons and fears concerned confusion and help him his administration at all level. Keywords depression, suicide, adolescence, rehabilitation health center
\end{abstract}

\section{Introduction}

The classification of psychiatric disorders is an area of controversy and particularly challenging in child and adolescent mental health. Accurate diagnostic classification can be used to predict benefit from treatment, predict duration, or severity of disorder and is central to etiological research.

A suicide is a deliberate act by someone to end his life, other argue that killing one self vaunted life, have views one suicide reflects of the courage the person committed suicide or cheese and are flections of failure and lack of need for the continuation of his life.

Recognized the world health organization as one of the "most is cope with of all disease in the world" Major Depression Disorder (MDD) is defined in the DSM-IV (Diagnostic and Statistical Manual for mental Disorders).

Insomnia/hypersomnia: Low-energy or fatigue, feeling of excessive guilt, indecision, poor concentration and memory. Recurrent thoughts of death or suicide.

\section{Risk factor for Depression}

1. Can be genetic-often precipitated by a major stressor (changing school, parents get divorced, breakup with boyfriend, girlfriend).

Differential Diagnosis for Depression disorder: 1-Bipolar disorder.

2. Dysthmic disorder (often over looked, but can cause as much, or move impairment in function than MDD due to extended course).

3. Substance abuse (often comorbid).

4. Anxiety disorder (often comorbid, especially in girls).
5. Conduct disorder (often especially in boys).

6. Bereavement.

7. Adjustment disorder with depressed mood.

8. Post-traumatic stress disorder.

9. Attention-deficit hyperactivity disorder.

\section{Protective factors against suicide}

Parenting skills that emphasize praise for positive behavior.

1. Increases amount of time that parents spend with children

2. Strong parent-family connectedness

3. Restricted access to guns or other weapons

4. Restricted access to alcohol, or other drugs

\section{Methodology}

1. Design of the study: Descriptive design use to depression and suicide into adolescence in health center.

2. Setting of the study: This study descriptive study way carried out in the health center during (18/11/2014-12/1/2015).

3. Selection of the sample: Purposeful sample of (50) adolescences patient.

4. Administrative permission: The study was proved by the committee in the college of nursing.

5. Statistical analysis: The descriptive statistics we used to analyze the results of the study.

\section{Results}

Table 1 shows that $46 \%$ of sample age ranged between 17 and 18 years and $24 \%$ of sample their age ranged between 12 and 
14 years. It also shows that $52 \%$ of the samples were female and $48 \%$ of the samples were male.

$68 \%$ of samples were not working and $32 \%$ of sample working. Also $64 \%$ of samples live in the town and $36 \%$ of the samples live in the village.

\section{Discussion}

Table 1 shows that the higher percentage of the study was among 17 to 18 years. This study results agreed with Lovelance. ${ }^{1}$ The level of anxiety in the age group because of the negligence of the diagnostic process by select depression function between the symptoms of anxiety and depression.

It shows that female had a higher percentage of the study than male. This study was in agreement with Culberlson, ${ }^{2}$ and $68 \%$ were without work. It may be because of their illness.

In most of our sample, $64 \%$ live in the town, and people live in the town are exposed to population more than those who live in the village. ${ }^{3}$

\begin{tabular}{|c|c|c|c|}
\hline & Variables & Frequency & $\%$ \\
\hline \multirow[t]{4}{*}{ Age } & $12-14$ & 12 & 24 \\
\hline & $15-16$ & 15 & 30 \\
\hline & $17-18$ & 23 & 46 \\
\hline & Average & 50 & 100 \\
\hline \multirow[t]{3}{*}{ Gender } & Male & 24 & 48 \\
\hline & Female & 26 & 52 \\
\hline & Average & 50 & 100 \\
\hline \multirow[t]{3}{*}{ Occupation } & Work & 16 & 32 \\
\hline & Not work & 34 & 68 \\
\hline & average & 50 & 100 \\
\hline \multirow[t]{3}{*}{ Living Area } & Town & 32 & 64 \\
\hline & Village & 18 & 36 \\
\hline & Average & 50 & 100 \\
\hline
\end{tabular}

\begin{tabular}{|c|c|c|c|c|}
\hline \multirow{2}{*}{ Variables } & \multicolumn{2}{|c|}{$\mathbf{F}$} & \multicolumn{2}{|c|}{$\%$} \\
\hline & Yes & No & Yes & No \\
\hline 1. Do you feel the sadness and depression? & 50 & 0 & 100 & 0 \\
\hline 2. Do you feel unhappy to the degree of painful? & 50 & 0 & 100 & 0 \\
\hline 3. Do you feel that your life is full of failure? & 48 & 2 & 96 & 4 \\
\hline 4. Are you satisfied with what is going on around you as you are in the past? & 50 & 0 & 100 & 0 \\
\hline 5. Do you feel guilt? & 49 & 1 & 98 & 2 \\
\hline 6. Do you feel disappointed in your self? & 40 & 10 & 80 & 20 \\
\hline 7. Do you blame yourself for every thing will happen? & 27 & 23 & 54 & 46 \\
\hline 8. Do you feel very uncomfortable and up set most of the time? & 49 & 1 & 98 & 2 \\
\hline 9. Do you like yourself? & 50 & 0 & 100 & 0 \\
\hline 10. Are you thinking about suicide? & 45 & 5 & 90 & 10 \\
\hline 11. Do you cry more new than I was previously? & 37 & 13 & 74 & 26 \\
\hline 12. Are lack concern for other? & 18 & 32 & 36 & 64 \\
\hline 13. Can you make decision as you would in the past? & 45 & 5 & 90 & 10 \\
\hline 14. Do you feel tired more than the previous? & 22 & 28 & 44 & 56 \\
\hline 15. Do you feel pay your self a strong impetus to do any work? & 15 & 35 & 30 & 70 \\
\hline 16. Do you feel any changing in sexual desire? & 18 & 32 & 36 & 64 \\
\hline 17. Do you feel fear for your health more than the previous? & 10 & 40 & 20 & 80 \\
\hline 18. Do you fear for your health pain to the point of warring? & 41 & 9 & 82 & 18 \\
\hline 19. Have you lost weight last period? & 20 & 30 & 40 & 60 \\
\hline 20. Do you feel that you appetite for food worse? & 20 & 30 & 40 & 60 \\
\hline 21. Do you feel you have achieved something his importance? & 25 & 25 & 50 & 50 \\
\hline 22. Do you worry there day easily? & 35 & 15 & 70 & 30 \\
\hline 23. Are you affected financial? & 32 & 18 & 64 & 36 \\
\hline 24. Do you have feel pessimistic for the future? & 40 & 10 & 90 & 20 \\
\hline 25. Do you have failed motional relationship? & 45 & 5 & 90 & 10 \\
\hline 26. Less illness or death of a member of person effected you? & 30 & 20 & 60 & 40 \\
\hline
\end{tabular}


Table 2 shows that $50 \%$ of patients feel the sadness and depression. Those patients have has a highly depression sense as an individual role of hopelessness. ${ }^{4}$

It also shows that $50 \%$ of patients are feeling unhappy to the degree of painful. $50 \%$ of patients are feeling that their life is full of failure. This study was in agreement with, ${ }^{5}$ and have a brooding sense of hopelessness about the future and feeling unhappy when potential and skill is able talent communicate objectives.

It also shows that $40 \%$ of patients feel disappointed in yourself because the patient does, ${ }^{6}$ and $18 \%$ dependent to the other, this study was agreement) not have the ability to attain its objective and this it depended on the other, however, that depressive feeling become in capable to achieve its objectives and keeps them busy.

It also shows that $45 \%$ of patients are thinking about suicide. This study was in agreement with Wilson. There is a certain relationship between depression and suicide as the ratio between the proportion of suicide between depressed than others to reach, ${ }^{7}$ and shows that $41 \%$ of patients fear for their health physical pain to the point of worrying. This study was in agreement with ${ }^{8}$, and the presence of a significant relationship between social isolation and pain dysfunction. The study shows that the necessity of therapeutics to normalize the overlap style that differs from the study other group. ${ }^{9}$

\section{Conclusion}

The result of this study concluded that:

1. Depression was high in study than other studies, higher prevalence of depression in adolescent patients with age between 17 and 18 years (46\%).

2. $50 \%$ of patients feel the sadness and depression.
3. $50 \%$ of patients feel unhappy to the degree painful.

4. $40 \%$ of patients feel disappointed in their self.

5. $45 \%$ of patients are thinking about suicide.

6. $41 \%$ of patients fear for their physical health pain to the point of worrying.

\section{Recommendation}

Through the final result, this study recommends the following:

1. Need to work on early detection of depressive symptoms to adolescences so that studies can emphasize about the negligence of the diagnostic process symptoms in this age group that leads to insanity and suicide.

2. To involve young people as possible of cultural experiences and benefit from their expertise. Since this leads to self-promote as well as reduces the decrease of pessimism and isolation. This would alleviate the depressive symptoms.

3. Attention to psychosocial and social support for young people, by creating a state of confidence as well as through the establishment of altrohed and programs that reduce the cases of grief and depression symptoms.

4. Work on understanding to explain emotions and its problems, difficulties experienced, discuss the reasons and fears concerned, confusion and help him his administration at all levels.

\section{Conflict of Interest}

None.

\section{References}

1. American Psychiatric Association. Diagnostic and Statistical Manual of Mental Disorders: DSM-5. 5th ed. Washington, DC: American Psychiatric Association; 2013.

2. Committee on Psychosocial Aspects of Child and Family Health and Task Force on Mental Health. Policy statement-the future of pediatrics: mental health competencies for pediatric primary care. Pediatrics. 2009:124(1):410-421.

3. Borowsky LW, Ireland M, Resnick MD. Adolescent suicide attempts: risks and protectors. Pediatrics. 2001:107:485-493.

4. Friendman RA. Uncovering and epidemic-screening for mental illness in teens. N Engl J Med. 2006;355:2717-2719.

5. Bell JL. The impact of social isolation, pain and physical dysfunction on depression among three elderly ethnic minority groups experiencing joint symptoms, UMI Dissertation Services. 2007

6. Ibrahim AS, Ibrahim R. Behavior in Health and IIIness. New York, NY Heart Stone Book; Carlton Press. 2009.

7. Lovelance GC. Anxiety among recently a admitted nursing how resistants, Precursor to clinical depression mai. 2007:35:30.

8. Seigmar EP, Klein DC, MillerWR. Depression. In H. Leitenberg (ed.) Hand Book of Behavior Modification and Behavior Therapy. 2006. New Jersey: Prentice Hall.

9. Walsin LR. Depression discorders, in. JL Jacobson and AH Jacobson: (eds), Psychiatric Secrets Philadelphia, PA: Mosby, 2008.

This work is licensed under a Creative Commons Attribution-NonCommercial 3.0 Unported License which allows users to read, copy, distribute and make derivative works for non-commercial purposes from the material, as long as the author of the original work is cited properly. 